\title{
An Attempt to Characterize Street Pharmaceutical Teachers Abusing Drugs and Aspect of Allergy Among Adult Men Attending Long Distance Institutions in Pune, India
}

\author{
Rahul Hajare* \\ Indian Council of Medical Research, India
}

Received: 阱 September 25, 2018; Published: 阱 October 01, 2018

*Corresponding author: Rahul Hajare, Adjuvant Professor Shikshan Vikas Mandal Trust, Indian Council of Medical Research, New Delhi, India

\begin{abstract}
In the India like all nations, drug abuse is seen as a social and health problem that has many serious implications for the physical, social, psychological and intellectual development of the victims more especially, the teaching Staffs. Therefore, it continues to be a concern to families, community leaders, educators, social workers, health care professionals, academics, government and its development partners. Though there some studies on drug abuse, there is none on teaching staffs and drug abuse focusing on the street teaching staffs the most vulnerable category. Street teaching staffs care hypothesized to be more at risk of any epidemic including drug abuse. This study sought to determine the risk and prevalence of drug abuse among street teaching staffs focusing on those in the car parks. The research was focused on six critical areas: knowledge of drug abuse, perception towards it, knowledge of the causes, knowledge of negative impacts of it, knowledge of the preventive methods; and knowledge of the support services needed by abusers. A structured questionnaire was used to collect the data from thirty-five participants (i.e. one driver and six casual apprentices from each of the five car parks) were interviewed. The data was presented and analyzed using tables and percentage. The findings revealed among others, that there is high level of awareness of drug abuse but the feeling towards it is mixed. Like other teaching staffs, street teaching staffs are abusing drugs mainly due to peer influence with the ultimate objective of getting high to relief stress, group recognition, trusted by peers, etc. Similarly, participants are highly aware of the negative impacts encompassing fighting, stealing, mental illness, etc. To finance the behavior, victims are engaged in all types of dangerous antisocial behavior including romantic ones exposing them to a range of diseases including, obesity, diabetes, ageing, epigenetic, window STIs and window HIV/AIDS. Ghutaka is the most commonly abused drug. Though in the minority, some have started experimenting cocaine/ coke. While participants have good knowledge of the critical methods to fight drug abuse, the support services needed by victims, victims are mostly reluctant to seek the services not only because they are hard to find but fear societal stigmatization, exclusion and discrimination and professionals' maltreatments.
\end{abstract}

Keywords: Drugs; Abuse; Street Teaching Staffs; Casual Van Apprentice; And Commercial Van Driver Role

\section{Executive Summary}

Single time itching reduces the inches of verified profile of human health. Traditionally proverb. Many illnesses including degeneration have a result of inadequate sanitation. The systems for taking dirty water and other low standard products away from institutions in order to protect teaching staff's health. Immunity brought many unconventional yet meets wisdom. Any diseases can be detected by our self-examination, that can a best examination ever or other screening measures before the symptoms become serious. Most cases have detected and diagnosed when other symptoms develop or developing. There are more than 10000 types of autoimmune diseases including breast cancer, skin cancer, lung cancer, colon cancer, prostate cancer, itching and lymphoma. Symptoms vary depending on the type and strength. Immunity can natural transition that club of biomedical changes that seen in human body progress. It can an early begin research topic that has been traditionally treated with force of attraction. Medically with a fairly low level of success and does not address the most significant result, which include depression, sign of fearness, poignant, barking and insomnia. Medicine has been shown in preliminary studies to address and treat specific symptoms of human lupus. Some studies show a significant improvement in symptoms compared to that of family history; however, these studies need to be reproduced on a larger scale to influence the medical community that has not familiar with therapy. 


\section{Introduction}

Drug abuse, the once silent killer is claiming more victims than ever before, and in horrific manners. In 2016, according to UN 250 million people between the ages of 15 and 64 used at least one drug in 2014 and more than 29 million are suffering drug use disorders compared with 27 million in 2013 [1,2]. Africa now occupies second position worldwide in the trafficking and consumption of illegal drugs. The UN estimate in 2014, there were 28 million drug users in Africa and 37,000 people die annually from diseases associated with the consumption of it. The teaching staffs are identified as the most vulnerable, especially those who cannot resist peer pressure. The India has witnessed increased in the abuse of cannabis, heroin, cocaine, ecstasy and other stimulant drugs were noted in the country. It is estimated more than $40 \%$ of illicit drugs users are under the age of 20 years to escape social problems. Because teaching staffs are the source of hope and inspiration for the society and need to be protected. Unfortunately, teaching staffs do not only live in poverty but tens of millions of them around the world find themselves living or working in the streets as street teaching staffs. However, research shows that the street teaching staff's phenomenon is not a new socio-economic problem. Although the number is unknown, existing estimates suggest that tens of millions of teaching staffs are street-based, and their numbers are rising secondary to global population growth, HIV epidemic, migration, and urbanization, UNICEF [3,4]. Despite few studies reporting prevalence there are no pooled data on the types of substance abused, reasons for abuse by teaching Staffs including the street teaching Staffs. Therefore, there is an urgent need to study street teaching staffs and drug abuse to both understand the magnitude of the problem and design programmes for prevention and rehabilitation.

\section{Area of Study}

The study was conducted in five car parks, Sinhagad road, Kennedy road, Baner road, Katraj road, camp road. In view of the volume of commuters, these car parks have become one of the busiest places in towns and growth centers and becoming favorite places for all types of teaching Staffs including street teaching staffs scavenging for better life through casual employment and petty trading.

\section{Data Collection Methods}

The data was collected by conducting individual interviews using a structured questionnaire with thirty-five participants (i.e. one driver and six apprentices from each car park). The questionnaire was divided into six sections, knowledge of drug abuse, causes, negative impacts, preventive methods, support services needed by abusers; and perception towards it.

\section{Data Analysis Methods}

The analysis was in two folds: coding and creation of tables, preparation of variables by combining codes, converting codes into variables or developing new ones. This was used to provide a summary of patterns that emerged from responses.

\section{Limitations of the Study}

Literature: though there are many similar studies in this area, but few are on the studied population and none was conducted in the small cities of India.

Funding: there was not a single financial support from any institution or individual despite all efforts.

Sensitivity of the topic: because of the sensitivity of the topic, I have encountered many problems in getting respondents especially the casual apprentices who are willing to talk to me without unnecessary delay.

\section{Objectives of the study}

The rationales were to research into drugs abuse by street teaching staffs focusing on those in the car parks and commercial drivers.

\section{Significance of the Study}

a) Contribute to existing knowledge.

b) Act as an input for policy and law makers.

c) Provide a base for the protection of students.

d) Will be useful to student rights advocates.

e) Will increase people knowledge of the risk of drug abuse by teaching staffs in car parks.

\section{Definition of Concepts}

Drugs: are those man-made or naturally occurring substances used without medical supervision basically to change the way a person feels, thinks or behaves by altering the normal biological and psychological functioning of the body especially the nervous system [5].

Abuse: a drug is considered abused by a person when s/ he deliberately uses it for non-medical purposes, as well as the arbitrary use without medical prescription.

\section{Street Teaching Staffs}

Any person (27 to 47 years) who spends majority of his time in car parks sometimes working or roaming; and have limited or no contact with a family and spend both days and nights in the car parks without returning to a family or a guardian.

Commercial Van Driver: Any male person who control operation and movement of a motorized vehicle for transporting more than nine persons including himself on public road for payment and for a distance not more than 90 kilometers [6].

Casual Van Apprentice: Any staffs who do not have regular hours to learn driving from a driver with or without wage and is only engaged when the need arises. 


\section{Ethical consideration}

Thought the study was non-invasive, to accord priority to respondents' welfare, major ethical consideration was made. Explaining study objectives to obtain verbal permission, participants' determining interview venues; and right to stop participating at any time.

Data Presentation, Interpretations and Discussions: Hence maturity is a critical stage in life and is the most transformative period, it is fundamental that teaching staffs are protected from the devastative effects of drug abuse $[7,8]$. To protect them, it is critical that among others, knowledge of drug abuse, causes, negative impacts, preventive methods, support services needed by abusers; and perception towards it is scientifically documented.

\section{Knowledge of Drug Abuse}

In reacting to whether they have ever heard of drugs, all responded in the positive. However, they reacted differently in commenting what it means: smoking illegal substances $[9,10]$ $18(31.03 \%)$, drinking illegal drinks $11(18.96 \%)$, misused of drugs $8(13.79 \%)$, excessive drug use $7(12.06 \%)$, unauthorized drugs use 6 (10.34\%), and others specified 5 (8.62\%). In a following up question as to whether they know any type of drugs in the community, they reacted with opium 17 (26.15\%), alcohol 9(13.84\%), inhalant $7(10.76 \%)$, antibiotics $3(4.61 \%)$, etc. While majority $28(93.33 \%)$, claimed to have seen drugs in the community, in a related question as to the types seen in the community, they reacted as follow, alcohol 19 (21.83\%), opium 15 (17.24\%), inhalant11 (12.64\%); and others specified 8 (9.19\%). In a follow up question as to whether drug abuse is happening, majority 17 (68\%) responded in the affirmative. In the same vein, majority $21(70 \%)$ acknowledged that drug abuse is happening and have personally witnessed people being engaged in it. In a related question as to the age range seen abusing it, the respondents felt as follows, (18 to 22) 15(30\%), (13 to 17$) 12$ (24\%), (23 to 27$) 8$ (16\%), (8 to 12 ) 7 (14\%), and (33 to 37$) 5(10 \%)$. In reacting to which drugs are mostly abused, the respondents shared their views as, alcohol 19 (20.65\%), opium 13 (14.13\%), cocaine 11 (11.95\%), inhalant 8 (8.69\%), antibiotics 7 (7.60\%), hand others specified 4(4.34\%) respectively. In a follow up question as to why those drugs are mostly abused, they reacted like quick drunkenness/high 17 (23.61\%), make one's work hard and long 14 (19.44\%), easily accessible 11 (15.27\%), easily affordable 9 (12.50\%), long term drunkenness/high 7 (9.72\%), drunkenness not easily notice, and others specified 5(6.94\%) respectively.

\section{Perception Towards Drug Abuse}

In responding to how drug abuse is view in the community, participants lamented very bad $46(36.80 \%)$, bad $21(16.80 \%)$, normal $13(10.40 \%)$, punishment from God 11(8.80\%), negative effects of development $8(6.40 \%)$, a curse on the community $7(5.60 \%)$, a careless attitude $6(4.80 \%)$, a waste of the youths and a parental failure $4(3.20 \%)$, others specified (3); and predestined $2(1.60 \%)$. In a related question as to how the community considers abusers, respondent shared criminals and thieves 27 (20.00\%), dangerous 25(18.51\%), lazy and unproductive 21(15.55\%), aimless and good for nothing 20(14.81\%), cursed and a societal burden $13(9.62 \%)$, disbelievers and evils $9(6.66 \%)$, shameless and disappointing, and failures $7(5.18 \%)$ respectively, wealthy $4(4)$; and others specified $2(1.48 \%)$. Commenting on how they view abusers in the community, they reacted as sometimes dangerous $27(23.88 \%)$, thieves and unreliable $12(10.61 \%)$, always dangerous, aimless and wasteful 11(9.73\%) respectively, sometimes friendly $9(7.96 \%)$, useless and wealthy $7(6.19 \%)$ respectively, sympathetic and cursed 5(4.42\%) respectively; and other specified 2(1.76\%). Responding to whether teaching staffs abused drugs, majority $21(70.00 \%)$ responded in the affirmative. In a follow up question as to which categories of teaching staffs are likely to abuse drugs, respondent reacted as mapped out.

College drop outs 21(13.29\%), street teaching staffs $19(12.02 \%)$, teaching staffs of jobless parents and teaching staffs of drug abusers $18(11.39 \%)$ respectively, teaching staffs from poor family $16(10.12 \%)$, teaching staffs of homeless parents $15(9.49 \%)$, poor performing street teaching staffs $14(8.86 \%)$, orphans $12(7.59 \%)$, single parent teaching staffs $10(6.32 \%)$, teaching staffs of divorced parents $9(5.69 \%)$ and teaching staffs from the provinces 3(1.89\%); and others specified 1(0.63\%). Reacting to why teaching staffs, abuse drugs, respondents felt differently. Peer influence 29(14.87), pleasure and brevity seeking 24(12.30), poor academic achievements 22(11.28), unstable/broken home environment 21(10.76), easy affordability 19(9.74), ignorance and poverty $17(8.71)$, curiosity and weak law enforcement $16(8.20)$, easy accessibility 14(7.17), not fearing of parents/adults in the community 11(5.64), to work hard and for long hours 10(5.12) respectively; and others specified 2(1.02). Commenting on where the teaching mostly abuse drugs, participants opined. Peers' homes 26(19.25\%), street corners 25(18.51\%), car parks 21(15.55\%), night and video clubs and ghettoes and during parties $14(10.37 \%)$ respectively, colleges and college sides $9(6.66 \%)$, their own homes living without ventilator $4(2.96 \%)$, and other specified $2(1.48 \%)$. While majority $23(76.66 \%)$ claimed to have heard teaching staffs who works and live in car park abusing drugs, majority $21(70.00 \%)$ equally confirmed to have seen some abusing drugs in the car parks. In a related question as to how these teaching get the drugs, participants felt as captured. Peers offered them 25(24.03\%), buying them jointly $21(20.19 \%)$, adults abusers offered them $13(12.50 \%)$, picking remains in streets $11(10.57 \%)$, stealing $10(9.61 \%)$, as gifts for a service to drug dealers and buying them individually $9(8.65 \%)$ respectively, payment for a service including romantic ones 5(4.80\%); and other specified $1(0.96 \%)$.

\section{Causes of Street Teaching Staffs Abusing Drugs}

Commenting on why teaching in the car parks abuse drugs, respondents reacted differently. Peer influence and group recognition 33(15.63\%), lack of parental supervision $27(12.79 \%)$, curiosity 23(10.90\%), lack of stable home environment 21(9.95\%), 
to work hard and for long hours $20(9.47 \%)$, to relieve stress and ignorance $19(9.00 \%)$ respectively, easy accessibility $18(8.53 \%)$, for seeking pleasure and relaxation $17(8.05 \%)$, easy affordability $12(5.68 \%)$; and others specified $2(0.94 \%)$. Reacting to perceived benefits of drugs abuse by the teaching staffs in the car parks, respondents felt as follows: feeling high 31(19.62\%), feel accepted and trusted by peers $29(18.38 \%$ ), drowsiness $26(16.45 \%)$, ability to work hard and for long hours 25(15.82\%), brevity 19(12.02\%), ability to focus or concentrate $18(11.39 \%)$, ability to think/ memorize quickly $7(4.43 \%)$; and others specify 3 (1.89\%).

\section{Negative Impacts of Drug Abuse}

In addition to vast majority 25(83.33\%) subscribing to drug abuse having negative impacts on the street teaching staffs, in a follow up question regarding the negative impacts, participants reacted as mapped [11,12]. Alzheimer's disrupts 26(13.04\%), Mental illness 31(16.14\%), aggressive behavior 27(14.06\%), problems and fighting at work place $24(12.50 \%)$, endless problems with peers and colleagues 22(11.45\%), frequent fighting and stealing 20(10.41\%), becoming a college drop-outs 19(9.89\%), endless family problems 18(9.37\%), getting diseases (e.g. window HIV/AIDS, TB, EARLY STIs and Psoriasis etc.) 12(6.25\%), road accidents $9(4.68 \%)$, stroke $5(2.60 \%)$; and other specified $4(2.08 \%)$. Lamenting on the types of drugs mostly abuse by the street teaching staffs, respondents opined differently. Inhalant 26(22.22\%), alcohol 17(14.52\%), antibiotics 13(11.11\%), opium 11(9.40\%), diazepam 7(5.98\%), hashish and heroine 5(4.27\%) respectively, others specified $4(3.41 \%)$; cocaine and paracetamol $1(0.85 \%)$.

\section{Summary and Conclusion}

The findings revealed high awareness of drug abuse is high, its causes, impacts, methods of financing; and prevention. It has seen most street teaching staffs has abusing drug middle of the time table and lunch time. Some students and street teaching staffs combined abusing drugs [13]. The attitude towards it is mixed. Teaching staffs including street teaching Staffs are abusing it. Urgent actions needed to rehabilitate and protect them.

\section{Recommendation}

To ameliorate the high risk, rehabilitate victims, and safeguard the last hope of our communities, it is recommended that: Redouble their supervisory endeavors by regularly monitoring their teaching staff's activities. Continuously engage their teaching staffs in open discussions both to know what is affecting them and share with them the negative effectives of antisocial behaviors including drug abuse. Support their teaching staffs to develop strong personalities, resistant skills, self-esteem building techniques, etc. to avoid bad peers' victimization, avoid degenerative practices, and avoid abusive behaviour principal of the college. Avoid weakens leaders' and weaken principal of the college.

\section{Acknowledgment}

This study has been guided by under supervision and guidance of Renowned Laboratory Scientist Respected Dr. Ramesh Paranjape' Retd. Director and Scientist ' $G$ ' National AIDS Research Institute India. I express my sincere gratitude towards Respected Sir' for motivation and being great knowledge source for this research.

\section{References}

1. Abhay M (2017) Substance abuse among street children in Mumbai. Vulnerable Children and Youth Studies 3(1): 42-51.

2. Laudet AB (2006) The Role of Social Supports, Spirituality, Religiousness, Life Meaning and Affiliation with 12-Step Fellowships in Quality of Life Satisfaction Among Individuals in Recovery from Alcohol and Drug Problems. Alcoholism Treatment Quarterly 24(1-2): 33-73.

3. Rahul Hajare (2018) Shocking link of rsapid rise in pre-cancer among the healthy adults in pharmaceutical institution Pune University India living with low oxygen and poor sanitation environment: Affordable treatment rate three-times over. APTI Bulletin - Continuing Education 19(113).

4. Rahul Hajare (2018) An Attempt to Eradicate Alcohol Dependency from Adult Men in Service Privately Managed Pharmaceutical Institutions in India. Toxi App Phar Insig 1(1): 2.

5. Rahul Hajare (2018) Depression-Level Effectiveness of the Curse Words in Young Adults in Pune University. Ann Rev Resear 2(4).

6. Rahul Hajare (2018) The True Principal Health and Investigation of The High Burnout Stages Experienced by Professors Working in Pharmacy Institutions Pune University and Related Factors: An Important Study. Medical Research and Clinical Case Reports 1: 66-72.

7. Rahul H (2018) Detection of High Addictive Habits Circulating Office in Charge of Private Pharmacy Institutions in Pune University India (Evidence Based Study of Late Report Office in Charge to College). Biomed J Sci\&Tech Res 6(2).

8. Rahul H (2018) Co-Relation of Domestic Violence and Epileptic Seizure ("Fit") Experience Among Recently Married Women Residing in Slums Communities' Pharmaceutical Institutions in Pune District, India. Glob J Intellect Dev Disabil 4(5).

9. Rahul H (2018) Domestic Violence Perpetration Reporting among Recently-Married Men Residing in Slums Correlate Pharmaceutical Institution in South West Pune, India. Orthop \& Spo Med Op Acc J 1(3).

10. Rahul H (2018) Relationship between emotional intelligence and variation of high risky behavior in private pharmacy institutional principal and assistant professor combined attending from long distance driver role in pune university, India: An Attractive Findings. JOJ $\operatorname{scin} 1(4): 555567$.

11. Rahul H (2018) Indian Women, Trauma and Hydroxyl Drugs Dependency: Connections and Disconnections in Heart Disease for Women. Int J Curr Innov Adv Res 1(2): 1-2.

12. Rahul A Hajare (2018) Formulas and Symptoms of Adrenal Fatigue Syndrome (AFS) of Adult Men. Orthop \& Spo Med Op Acc J 1(3).

13. Rahul Hajare (2018) Extra-Marital Affair Can Lead Trauma and Connections in Higher Risk for Heart Disesase in Indian Women. Drug Des Int Prop Int J 2(1). 
(c) (i) This work is licensed under Creative

To Submit Your Article Click Here: Submit Article

DOI: 10.32474/CTGH.2018.01.000118

$\begin{gathered}\text { Current Trends in Gastroenterology } \\ \text { and Hepatology }\end{gathered}$
Assets of Publishing with us
- Global archiving of articles
- Immediate, unrestricted online access
- Rigorous Peer Review Process
- Authors Retain Copyrights
- Unique DOI for all articles

